\title{
Phylogenetically diverse Escherichia coli strains from chicken co-harbour multiple carbapenemase encoding genes (blaNDM-blaOXA-blaIMP)
}

\author{
Erkihun Aklilu 1,2*, Azian Harun 2*, Kirnpal Kaur Banga Singh ${ }^{2}$, Shamsaldeen Ibrahim ${ }^{1}$, Nor \\ Fadhilah Kammaruzzaman ${ }^{1}$
}

${ }^{1}$ Faculty of Veterinary Medicine Universiti Malaysia Kelantan, Locked Box 36, Pengkalan Chepa 16100 Kota Bharu, Kelantan, Malaysia

${ }^{2}$ Department of Parasitology and Microbiology, School of Medical Sciences, Universiti Sains Malaysia, 16150 Kubang Kerian, Kota Bharu, Kelantan, Malaysia

* Correspondence: erkihun@umk.edu.my; azian@usm.my Tel.: +60-97717236 (E.A.), +60-97676282 (A.H.)

\begin{abstract}
Carbapenem resistant Enterobacteriaceae (CRE) has been public health risk in several countries and recent reports indicate the emergence of CRE in food animals. This study was conducted to investigate the occurrence, resistance patterns, and phylogenetic diversity of CRE E.coli from chicken. Routine bacteriology, PCR detection of E.coli species, multiplex PCR to detect carbapenemase encoding genes and phylogeny of CRE E. coli were conducted. The results show that $24.36 \%$ (19/78) were identified as CRE based on the phenotypic identifications of which 17 were positive for the tested carabanemase genes. The majority, $57.99 \%$ (11/19) of the isolates harbored multiple carbapenemase genes. Four isolates harbored all blaNDM bla OXA, blaIMP, five and two different isolates harbored blaNDM and blaOXA, and blaOXA and blaIMP respectively. The Meropenem, Imipenem and Ertapenem MIC values for the isolates ranged from $2 \mu \mathrm{g} / \mathrm{mL}$ to $\geq 256 \mu \mathrm{g} / \mathrm{mL}$. Phylogenetic grouping showed that the CRE E.coli isolates belonged to five different groups; groups A, B1, C, D and unknown. The detection of carbapenem resistant E.coli in this study shows that CRE is has become an emerging problem in farm animals, particularly, in poultry farms. This also implies the potential public health risks posed by CRE from chicken to the consumers.
\end{abstract}

Keywords: Carbapenem resistant Enterobacteriaceae (CRE), E.coli, Antimicrobial Resistance, Multidrug resistance, Phylogenetic diversity, chicken, food animals, Antimicrobials

\section{Introduction}

Carbapenem resistance in Enterobacteriaceae is a serious emerging antimicrobial resistance (AMR) issue that has been escalating and posing challenges in treating infections caused by the 
resistant bacteria. In recent years, studies have indicated that, Carbapenemases have been increasingly identified in Enterobacteriaceae. Enterobacteriaceae are inhabitants of the intestinal flora and are among the most common human pathogens that causes cystitis and pyelonephritis with fever, septicaemia, pneumonia, peritonitis, meningitis, and device-associated infections [1]. The bacteria in this family are transmitted easily between human and animals, especially via fomites, food and water. During the transmission, genetic materials are transferred through horizontal gene transfer, mediated mostly by plasmids and transposons. Enterobacteriaceae are among the common nosocomial pathogens often causing infections through medical devices that include ventilators, intravenous catheters, urinary catheters, or wounds caused by injury or surgery [2]. Such nosocomial infections commonly affect immunocompromised patients and in patients being treated using invasive devices. Carbapenem is a broad spectrum Beta lactam antibiotic that is regarded as the last-line antibiotic, especially to be used in critically ill patients who have developed antimicrobial-resistant bacterial infection. Unfortunately Enterobacteriaceae have developed resistance against this last resort drug and made it ever challenging to treat infections caused by diseases caused by these carbapenem resistant Enterocateriaceae (CRE). Among the bacteria in the family Enterobacteriaceae, Escherichia coli and Klebsiella pneumoniae are the most commonly detected CRE that has been posing threat to the public health and animal health [3]. Such prevailing AMR issue has been compromising the efficacy of antibiotics and according to the World Health Organization, there is a possibility for the world to encounter an era, in which all the antibiotics become ineffective thereby increasing mortality rate and increasing cost of treatment if no intervention is done to overcome the problem. There are also concerns that failure to counter the rising AMR problems worldwide may lead to re-emergence of previously eradicated or controlled diseases [4].

According to the National Surveillance of Antimicrobial Resistance (NSAR) in Malaysia from 2006 to 2017, which analysed the data obtained from hospital microbiology laboratories from different parts of the country, carbapenem resistance in E. coli declined from $0.5 \%$ in 2010 to $0.2 \%$ in 2014 [5]. However, there are no recent and comprehensive studies conducted on the prevalence of CRE in the country, particularly in agricultural sectors including farm animals and animal products. Moreover the data on the phylogenenetic diversity, antimicrobial resistance profiles and diversity in carbapenemase resistance encoding genes in E. coli from food animals, particularly chicken are scarce. Therefore this study was conducted to detect the presence of carbapenem resistant E.coli in live chicken, investigate the antimicrobial resistance patterns, determine the phylogeny and identify the common carbapemase genes in carbapenem resistant E.coli isolates from live chicken.

\section{Results}

2.1 Bacterial isolation, identification and antimicrobial resistance patterns

Based on the routine microbiology, 56.67\% (85/150) of the cloacal swab samples were positive for E.coli. However, further confirmation using E.coli species specific PCR confirmed that $91.67 \%$ $(78 / 85)$ of the presumptive isolates as E.coli. Overall, the PCR results showed that 52\% (78/150) detection rate of E.coli from the cloacal swab samples collected. The resistance pattern of E.coli 
isolated from chicken cloacal swab showed that most of the E.coli isolates (87.18\%) were resistant to Streptomycin followed by Ceftriaxone (80\%), Trimethoprim sulfamethoxazole (66.7\%), Ceftazidime (33.3\%), Meropenem (32.05\%), Ertapenem (30.77\%), Doripenem (29.5\%), Imipenem and Ciprofloxacin $(26.92 \%)$.

\section{Multiplex PCR detection of carbapenem resistance econcoding genes (blaIMP, blaNDM, blaKPC, blaOXA)}

The PCR result confirmed the presence of carbapenemase genes in the identified E.coli isolates. Out of the 78 E.coli isolates, 19 (24.36\%) were positive for at least one of carbapenemase genes. Among these, $57.99 \%(11 / 19)$ were positive for multiple carbapenemase genes. Four isolates harbored all blaNDM, blaOXA, blaIMP, five and two different isolates harbored blaNDM and blaOXA, and blaOXA and blaIMP respectively. However, none of the isolates were positive for blaKPC (Figure1 and Table 1).

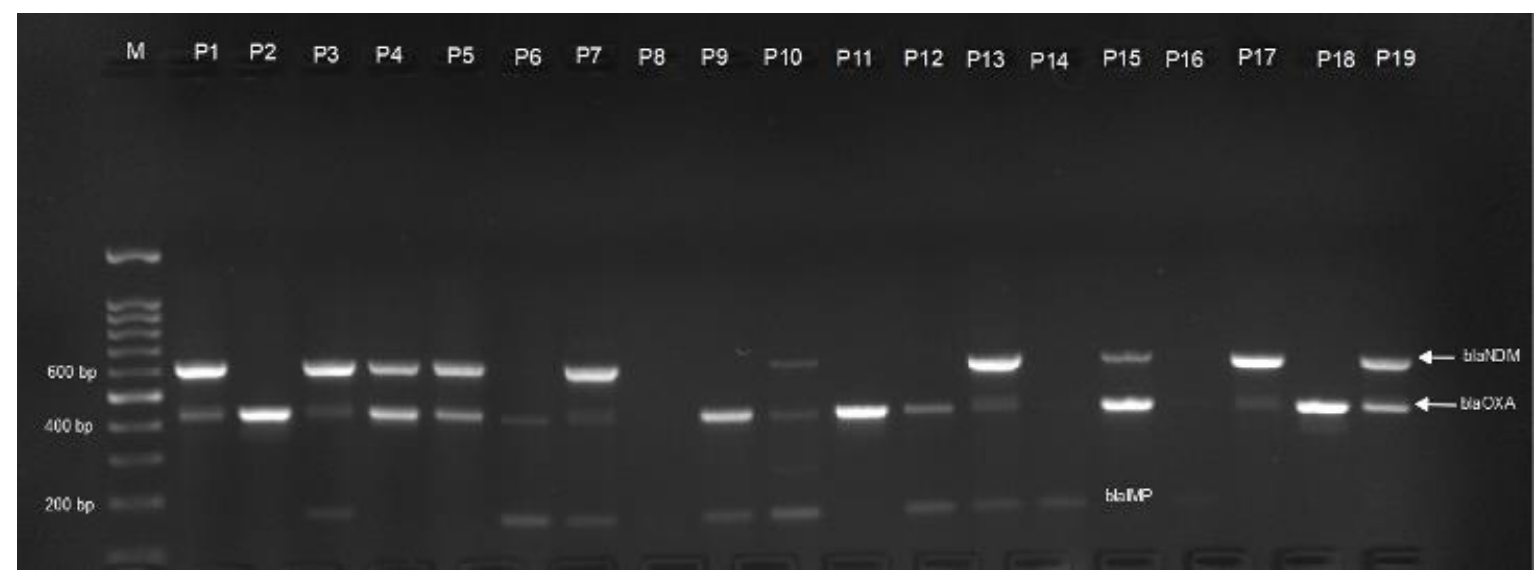

Fig 1. Multiplex PCR results for carbapenamse genes (bla KPC, blaNDM, bla $\mathrm{OXA}$ and bla IMP) of $E$. coli isolates from chicken identified as CRE phenotypically. M, 100bp DNA marker, Lanes P1-P19, test samples (E. coli) isolates.

Table 1. Antimicrobial resistance profile and phylogenetic diversity of CRE isolated from cloacal swab samples from chicken.

\begin{tabular}{cccc}
\hline Isolate & Antimicrobial & & Carbapenem Resistance \\
ID & Susceptibility & E-Test MIC Value & (Carbapenemase encoding genes) \\
\hline
\end{tabular}




\begin{tabular}{|c|c|c|c|c|c|c|c|c|c|c|c|}
\hline & \multicolumn{2}{|c|}{$\begin{array}{c}\text { (Disc } \\
\text { Diffusion) }\end{array}$} & \multirow[b]{2}{*}{$\begin{array}{c}\text { IMP } \\
(10 \mu \mathrm{g})\end{array}$} & \multirow[b]{2}{*}{$\begin{array}{c}\text { ETP } \\
(\mu \mathrm{g} / \mathrm{mL})\end{array}$} & \multirow[b]{2}{*}{$\begin{array}{c}\text { MEM } \\
(\mu \mathrm{g} / \mathrm{mL})\end{array}$} & \multirow[b]{2}{*}{$\begin{array}{c}\text { IMP } \\
(\mu \mathrm{g} / \mathrm{mL})\end{array}$} & \multirow[b]{2}{*}{ blaKРC } & \multirow[b]{2}{*}{ blaNDM } & \multirow[b]{2}{*}{ blaOXA } & \multirow[b]{2}{*}{ blaIMP } & \\
\hline & $\begin{array}{c}\text { ETP } \\
(10 \mu \mathrm{g}\end{array}$ & $\begin{array}{l}\text { MEM } \\
(10 \mu \mathrm{g})\end{array}$ & & & & & & & & & \\
\hline P1 & S & $\mathrm{R}$ & $\mathrm{R}$ & 8 & $\geq 256$ & 4 & - & + & + & - & Group B1 \\
\hline P2 & $S$ & $S$ & $\mathrm{R}$ & 6 & 8 & 16 & - & - & + & - & Group C \\
\hline P3 & $\mathrm{R}$ & $\mathrm{R}$ & $\mathrm{R}$ & 32 & $\geq 256$ & 32 & - & + & + & + & Group A \\
\hline $\mathrm{P} 4$ & $\mathrm{R}$ & $\mathrm{R}$ & $\mathrm{R}$ & 4 & $\geq 256$ & 4 & - & + & + & - & Group A \\
\hline P5 & $\mathrm{R}$ & S & $\mathrm{R}$ & 8 & 32 & 32 & - & + & - & - & Group A \\
\hline P6 & $\mathrm{R}$ & $\mathrm{R}$ & $\mathrm{R}$ & 4 & 6 & 8 & - & - & + & - & Group A \\
\hline P7 & $\mathrm{R}$ & $\mathrm{R}$ & $\mathrm{R}$ & 2 & 32 & 32 & - & + & + & + & Group A \\
\hline P8 & S & S & $\mathrm{R}$ & 4 & 6 & 32 & - & - & - & - & Group A \\
\hline P9 & $\mathrm{R}$ & S & $S$ & 32 & 8 & 32 & - & - & + & + & Group C \\
\hline P10 & $\mathrm{R}$ & $\mathrm{R}$ & $\mathrm{R}$ & 16 & 32 & $\geq 256$ & - & + & + & + & Group D \\
\hline P11 & $\mathrm{R}$ & $\mathrm{R}$ & $\mathrm{R}$ & 4 & 0.25 & 32 & - & - & - & + & Group B1 \\
\hline P12 & $\mathrm{R}$ & S & $\mathrm{R}$ & 8 & 16 & 8 & - & - & + & + & Group A \\
\hline P13 & $\mathrm{R}$ & $\mathrm{R}$ & $\mathrm{R}$ & 2 & 4 & 8 & - & + & + & + & Group B1 \\
\hline P14 & $\mathrm{R}$ & $\mathrm{R}$ & $\mathrm{R}$ & 2 & 1.5 & 6 & - & - & - & + & Group A \\
\hline P15 & S & $\mathrm{R}$ & $\mathrm{R}$ & 0.25 & $\geq 256$ & 4 & - & + & + & - & Group B1 \\
\hline P16 & S & $S$ & $\mathrm{R}$ & 6 & 4 & 8 & - & - & - & - & Group C \\
\hline P17 & $\mathrm{R}$ & $S$ & $\mathrm{R}$ & 0.25 & 32 & 6 & - & + & + & - & Unknown \\
\hline P18 & $S$ & $S$ & $\mathrm{R}$ & 2 & 16 & 0.25 & - & - & + & - & Group B1 \\
\hline P19 & $S$ & $S$ & $\mathrm{R}$ & 0.25 & $\geq 256$ & $\geq 256$ & - & + & + & - & Group A \\
\hline
\end{tabular}

\section{Phylogenetic analyses}

The results from quadriplex PCR showed that the CRE E.coli belong to diverse phylogroups including, group A, groupB1, group C, group E, group D and group unknown. Among the 19 CRE isolates, nine were identified as members of group A while five, three and one were respectively typed as group B1, group C, group D and unknown group (figure 2 and table 1). 


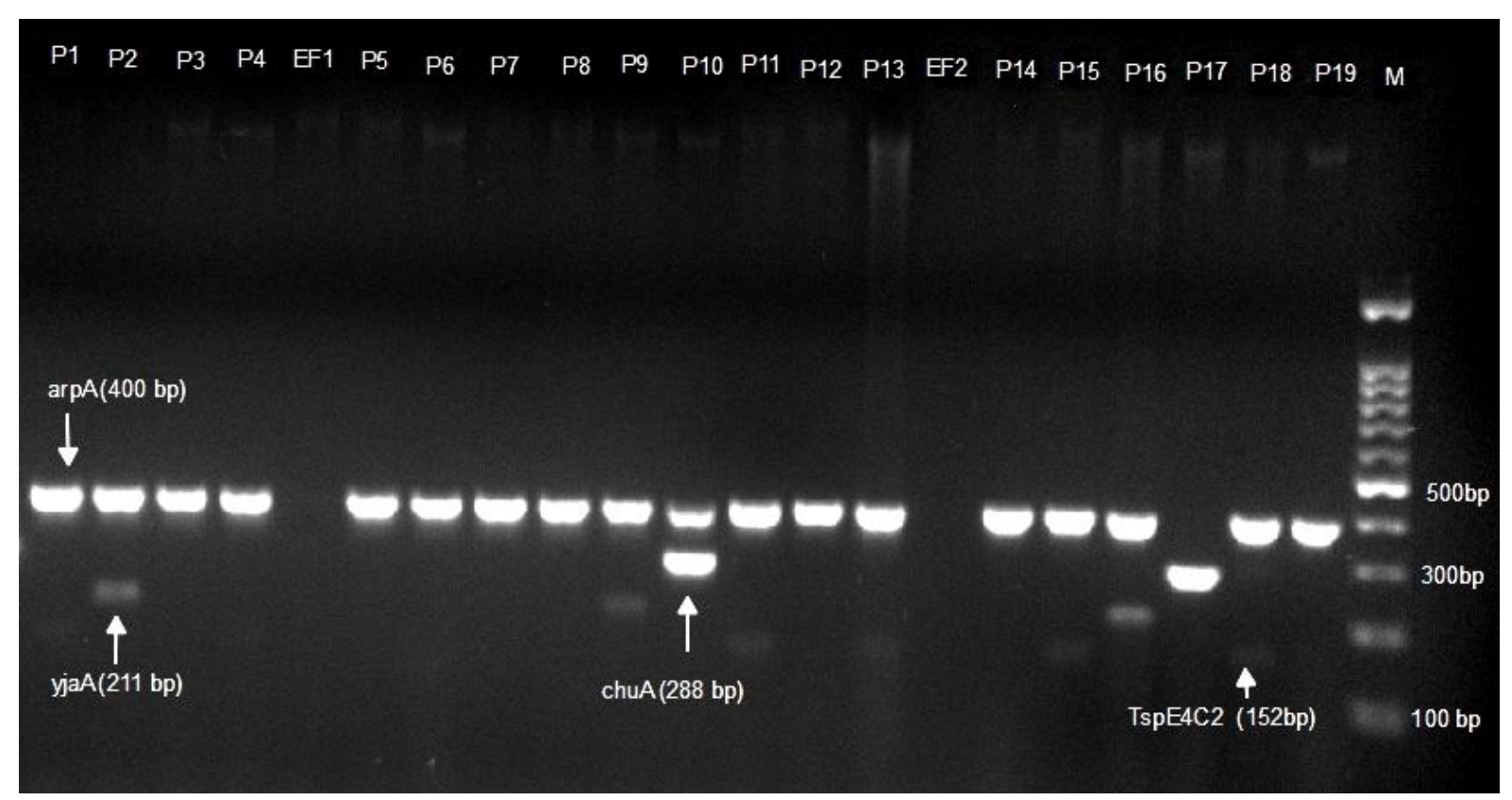

Figure 2. Quadruplex PCR profiles of new Clermont phylo-typing method. group A (P3, P4, P5, P6, P7, P8, + - - ) group B1 (P1, P11, P13, P18, + - +), group C (P2, P9, P16, + - + ), group E (P10, + + -); unknown (P17, - + - -); group D ( P10, + + - -); Lanes EF1 and EF2 (Escherichia fergusonii - - - -). 


\section{Discussion}

Antibiotic resistance is a global public health concern and the continuous emergence and spread of resistant bacteria has compounded the challenges in treating infections caused by antibiotic resistant bacteria. Carbapenem resistance in common bacterial pathogens has become one of the most concerning global public health issues since the carbapenem antibiotics are among the most critically important antimicrobials for treatment of infections in humans [6]. Carbapenems have been reported to show the broadest spectrum of antimicrobial activity in vitro against Gram-positive and Gram-negative bacteria, including anaerobes [7]. Because of their broad spectrum of actions, potency and effectiveness in treating broad range of infections in human, carbapenems have been recognized as the antibiotics of last resort to treat infections caused by multidrug-resistant Gram-negative bacteria [8]. Although Carbapenemases have been known to be new and potentially emerging problem in food-producing animals, the prevalence of carbapenem resistance in bacteria from animals have been scarcely reported [9]. So far most of the epidemiological studies and the significance of CRE have been focusing on human studies and the studies conducted in food animals have been very few. The current study reports relatively higher prevalence of CRE, $24.36 \%$ (19/78) of the total E. coli isolated from 150 colacal swab samples collected from broiler chicken from commercial farms based on phenotypic identifications of which 17 were positive for the tested carabanemase genes, whereas the two isolates were negative for carbapemmase genes while showing CRE positive results on MIC test by using Etest Strips. The majority, 57.99\% (11/19) of the confirmed CRE isolates harbored multiple carbapenemase genes. Four isolates harbored all blaNDM blaOXA-48, blaIMP, five and two different isolates harbored blaNDM and blaOXA-48, and blaOXA-48 and blaIMP respectively. A similar study from Egypt conducted on CRE particularly on carbapenem-resistant K. pneumoniae in broiler chickens from different farms, drinking water from the farms and workers handling the chickens reported a prevalence rate of $15 \%$ and $6 \%$ respectively from the broilers water samples. Among the poultry CRE isolates $(n=15)$, all of were blaNDM positive, while blaKPC, blaOXA48 and blaNDM genes were detected in 11 of the isolates while four isolates were positive for either blaKPC or blaNDM or blaOXA-48 and blaNDM. The same study also reported a high prevalence, $56 \%$ of K. pneumoniae isolates from humans harbouring multiple genes [10]. This finding suggests that a high incidence of CP K. pneumonia in humans may contribute to its dissemination among food-producing animals and the livestock environment, thus increasing the risk of foodborne transmission to the consumers [10]. The presence of carbapenem resistance in bacteria from animals, including food-producing animals (pigs, bovines and horses) has also been reported from some European countries such as Germany, France and Belgium [9]. The identification of E.coli isolates harbouring multiple (at least two) carbapenemase encoding genes from food animal in this study differentiates it from previous similar studies which mostly reported E. coli isolates harbouring one or two carbapenemase genes $[11,12]$.

Carbapenems are not routinely used in food animal production including poultry farming; however, carbapenem resistance in the E.coli isolates might have coevolved along with resistance to other antibiotics that are commonly used in resistant strains of bacteria may also be disseminated through direct contact, insect vectors, and other animals [8, 13, 14]. An earlier study by Poirel et al.[15] also suggested that co-selection of carbapenemase genes under the selection pressure imposed by the 
use of aminopenicillins and aminopenicillin- $\beta$ - lactamase inhibitor combinations in livestock may lead to the emergence and spread of carbapenem resistance. Reports from previous studies indicated that CRE can persist in animal production if the bacteria are adapted to animals and the farm environment and are stabilized by co-expression of further resistance genes [16, 17]. The possibility that infected or carrier humans, particularly the farm workers might spread resistant bacteria in farms through direct and direct routes of transmission cannot be ruled out. This is due to the fact that humans, the farm workers in the context of the current study are more likely to have been exposed to broad-spectrum antibiotics, and in particular to broad-spectrum b-lactams, than the chickens [14]. Since CRE can transmit through ddirect anthropozoonotic or zooanthroponotic routes [18], the spread of CRE in humans may pose risk for food animal production and possibly lead to the establishment of CRE in the food animal production ecosystem and may lead to subsequent further spread of these pathogens [16].

The Meropenem Imipenem and Ertapenem MIC values for the isolates ranged from $2 \mu \mathrm{g} / \mathrm{mL}$ to $\geq 256 \mu \mathrm{g} / \mathrm{mL}$. Most of the E.coli isolates were resistant to at least two antibiotics including including Meropenem and Ertapenem and Imipenem showing multidrug resistance. Phylogenetic grouping showed that the CRE E.coli isolates belonged to five different groups, groups A (47.37\%), B1 (26.32\%), C (15.79\%), D (5.26\%) and Unknown (5.26\%). In agreement with the current findings, a study by Asadi et al. [19] reported that the majority (54.21\%) of E.coli isolates from chickens belonged to phylogroup A. However, contrary to the findings in this study, the authors reported that $32.53 \%$ and $7.22 \%$ of the E. coli isolates belonged to phylogroups D and B1 respectively. Coura et al. [20] reported that phylogroups A followed by B1are the most common phylogroups of E. coli obtained from broiler carcasses suggesting the possibilities of contamination by commensal strains of E.coli. Cordoni et al. [21] reported that out the 272 E. coli strains analyzed 132 were grouped in B2 phylogroup, 61 in A1, 37 in group A and 21 in groups B1 and D while the remaining 21 were not ascribable to any group. Ramadan et al. [22] also reported that higher frequencies of virulent phylogroups of D and B2 were found among APEC isolates and phylogroup A in 25\% of APEC isolates, which is predominantly associated with commensal E. coli which might have originated from commensal E.coli strains that might have acquired virulence-related genes. Interestingly, previous studies by Walk et al. [23], demonstrated that the majority of E. coli strains that are able to persist in the environment belong to the B1 phylogenetic group. Earlier studies classifying the different E.coli phylogroups reported that the extraintestinal pathogenic strains usually belong to groups B2 and D, the commensal strains to groups A and B1, whilst the intestinal pathogenic strains belong to groups A, B1 and D [24]. In this study, discrepancies between the different methods for CRE detection have been observed. Some of the isolates appeared to show susceptibility towards the tested carbapenem antibiotics when tested by disc diffusion, but were confirmed to be resistant as seen from the results from MIC determination by E-test and PCR detection of carbapenmase genes. This discrepancy can be attributed to the different levels of discriminatory abilities of the tests. In general, antimicrobial susceptibility by disc diffusion is the least reliable compared to MIC determination and PCR. Both phenotypic and molecular detection and characterization of CRE have their respective limitations and reliable monitoring of CRE from animals requires a combination of molecular and culture-based methods [18]. 


\section{Materials and Methods}

\subsection{Ethics}

This research was reviewed and approved by the animal research ethics committee at the Faculty of Veterinary of Veterinary Medicine, Universiti Malaysia Kelantan.

4.2 Sample collection and processing, Bacterial Isolation and Identification

A total of 150 samples of cloacal swabs from live chickens in poultry farms in Kelantan were collected and placed in transport media. All the samples were collected aseptically and were placed in icebox during transportation and stored in refrigerator at $4{ }^{\circ} \mathrm{C}$ overnight and were processed the following day. The cloacal swabs were placed in $10 \mathrm{ml}$ of Phosphate-buffered Saline (PBS) for enrichment and were aerobically incubated for $24 \mathrm{~h}$ at $37^{\circ} \mathrm{C}$. The enriched samples were cultured on Nutrient agar (Oxoid, UK) and MacConkey (Oxoid, UK) agars were incubated at $37^{\circ} \mathrm{C}$ for $24 \mathrm{~h}$. Following primary culture, bacteria growths showing lactose fermentation on the MacConkey agar (Oxoid, UK) and Gram negative were sub-cultured on MacConkey (Oxoid, UK) agar and . Nutrient agar to obtain pure colonies. Following secondary culture, lactose fermenting colonies on MacConkey agar were selected sub-cultured on Eosin Methylene Blue (EMB) (Oxoid, UK) agar $24 \mathrm{~h}$ at $37^{\circ} \mathrm{C}$. Bacterial colonies with green metallic sheen on EMB agar were screened and further biochemical tests were conducted to presumptively identify $E$. coli isolates. Further confirmation of E.coli was done by PCR detection of E.coli species specific gene. All the confirmed E.coli isolates were inoculated onto chromogenic selective agar, Brilliance ${ }^{\mathrm{TM}} \mathrm{CRE}$ (Oxoid, UK) selective agar. Inoculated plates were incubated overnight at $37^{\circ} \mathrm{C}$ and presumptive CRE E.coli were identified according to the manufacturer's guideline. Colonies with blue or pale pink colours were presumptively identified as CRE. All the isolates which did not show the expected colonial morphologies of CRE were further tested by PCR amplifications of common carbapenemase encoding genes.

\subsection{Antibiotic Sensitivity Test (AST)}

Antibiotic sensitivity test was done using Kirby-Bauer disk diffusion method on Mueller-Hinton Agar (MHA) (OXOID, UK) with all the identified isolates according to the Clinical and Laboratory Standards Institute (CLSI) guidelines [6]. Escherichia coli ATCC 25922 strain was used as quality control. Single colonies of E.coli isolates from overnight culture on Luria-Bertani (LB) agar (Firstbase, Singapore) was transferred to a test tube containing $10 \mathrm{ml}$ of $0.9 \% \mathrm{NaCl}$. The turbidity of the bacterial suspension was adjusted to that of $0.5 \%$ McFarland standard. The bacterial suspension was then uniformly streaked onto the entire surface of MHA. Antibiotic discs were then uniformly placed on the agar using a sterile tweezers. The antibiotic discs used were Streptomycin (S10), Gentamycin (CN10), Enroloxacin (ENR5), Ciprofloxacin (CIP5), Trimethoprim Sulfamethoxazole (SXT25), Ceftazidime (CAZ30), Ceftriaxone (CRO30), and Imipenem (IPM10), Meropenem (MEM10), Ertapenem (ETP10), Doripenem (DOR10). The media were incubated for $24 \mathrm{~h}$ at $37^{\circ} \mathrm{C}$. After incubation, zone of inhibition for each of the antibiotic discs was measured and the antibiotic susceptibility was determined based on CLSI guidelines [25]. 
4.4 Determination of Minimum Inhibitory Concentration (MIC) using E-Test

The MIC determination using E-test (Biomerieux, France) was done as recommended by the manufacturer. Briefly, overnight culture of E.coli was suspended in $10 \mathrm{~mL}$ normal saline $(0.9 \%$ $\mathrm{NaCl}$ ). The turbidity of the bacterial suspension was adjusted to that of $0.5 \% \mathrm{McFarland}$ standard. The bacterial suspension was then uniformly streaked onto the entire surface of MHA (Oxoid, UK). E-test strips (Biomerieux, France) interpretations of the results were done according to the CLSI standards [25]. Escherichia coli ATCC 25922 strain was used as quality control.

\subsection{Molecular Characterization of Carbapenem Resistant E.coli}

\subsubsection{DNA Extraction}

Following bacterial isolation and identification, genomic DNA extraction was performed for all the presumptive E.coli isolates using boiling method. One to two bacterial colonies from each of the isolates on Nutrient agar were re-suspended into a $1.5 \mathrm{ml}$ microcentrifuge tube containing $100 \mu \mathrm{L}$ of $10 \mathrm{mmol} / \mathrm{L}$ Tris- $\mathrm{HCl}$ buffer ( $\mathrm{pH}$ 8.0). The microcentrifuge tubes containing the samples were vortexed and spun. The suspensions were then boiled for 10 minutes to lyse the cells, followed by quickly chilling on ice for 5 minutes. Then, the tubes containing the suspensions were centrifuged at 12000rpm for 10 minutes. Following that, $100 \mu \mathrm{L}$ of the supernatant containing DNA from each of the microcentrifuge tubes were transferred into another $1.5 \mathrm{ml}$ microcentrifuge and the DNA quality was assessed using spectrophotometer and gel electrophoresis and DNA extracts with acceptable qualities were stored at $-20^{\circ} \mathrm{C}$ until further use.

\subsubsection{Molecular detection of E.coli and carbapenem resistance encoding genes}

PCR amplification was conducted to identify E.coli using primers Pho-F/Pho-R targeting the housekeeping genes of E.coli and carbapenemase encoding genes (blaNDM, blaOXA, blaIMP, blaKPC) as described earlier [1, 26]. 
Table 1: Primers for Amplification of E.coli-specific and carbapenam resistance encoding genes.

\begin{tabular}{llc}
\hline Primer & Sequence (5' $\left.{ }^{\prime} \mathbf{3}^{\prime}\right)$ & Expected Product Size (base \\
\hline Pho-F & GTGACAAAAGCCCGGACACCATAAATGCCT & 903 \\
Pho-R & TACACTGTCATTACGTTGCGGATTTGGCGT & 621 \\
blaNDM-F & GGTTTGGCGATCTGGTTTTC & 232 \\
blaNDM-R & CGGAATGGCTCATCACGATC & 438 \\
blaIMP-F & GGAATAGAGTGGCTTAAYTC & \\
blaIMP-R & TCGGTTTAAYAAAACAACCACC & 798 \\
blaOXA-F & GCGTGGTTAAGGATGAACAC & \\
blaOXA-R & CATCAAGTTCAACCCAACCG & \\
blaKPC-F & CGTCTAGTTCTGCTGTCTTG & \\
blaKPC-R & CTTGTCATCCTTGTTAGGCG & \\
\hline
\end{tabular}

The PCR reaction mixture was prepared in $0.5 \mathrm{ml}$ Eppendorf tube prior to addition of templates. Each microcentrifuge tube contained $25 \mu \mathrm{l}$ of the PCR Master mix, $1 \mu \mathrm{l}$ of $10 \mu \mathrm{m}$ each primer, and $18 \mu \mathrm{l}$ of sterile nuclease free water. Then, $5 \mu \mathrm{l}$ of DNA template was added to each tube. Sterile nuclease free water was used as negative control. All PCR amplifications were conducted using Thermal Cycler 1000 (BIO-RAD, USA). Amplification of E.coli specific gene (pho) was carried out using the following protocol: initial denaturation for 2 mins at $94^{\circ} \mathrm{C}$, followed by 35 cycles consisting final denaturation for $1 \mathrm{~min}$ at $94^{\circ} \mathrm{C}$, primer annealing for $1 \mathrm{~min}$ at $56^{\circ} \mathrm{C}$, DNA extension for $1 \mathrm{~min}$ at $72^{\circ} \mathrm{C}$, followed by final extension for $10 \mathrm{mins}$ at $72^{\circ} \mathrm{C}$, and holding at $12{ }^{\circ} \mathrm{C}$.

For the amplification of carbapenem resistant genes, the PCR reaction constituted $25 \mu l$ of the 2xPCR Master mix (Promega, USA), $1 \mu \mathrm{l}$ of $10 \mu \mathrm{m}$ of the three primer pairs, and $14 \mu \mathrm{l}$ of sterile nuclease free water. Amplification of Carbapenem resistant genes was conducted by the following thermal cyclic conditions: activation of thermostable hot-start DNA polymerase for 10 mins at $94^{\circ} \mathrm{C}$, followed by 36 cycles of amplification consisting of denaturation for $30 \mathrm{~s}$ at $94{ }^{\circ} \mathrm{C}$, primers annealing for $40 \mathrm{~s}$ at $52{ }^{\circ} \mathrm{C}$, and strand elongation for $50 \mathrm{~s}$ at $72{ }^{\circ} \mathrm{C}$, with 5 mins at $72{ }^{\circ} \mathrm{C}$ for the final extension, and holding for $12{ }^{\circ} \mathrm{C}$. Analysis of the PCR amplification products was done by using electrophoresis in a 1.5\% agarose gel at $100 \mathrm{~V}$ and $400 \mathrm{~A}$ for 40 mins in $1 \times$ TBE buffer. The DNA fragments were then visualized using GelDoc EZ Imager (BIO-RAD, USA). The DNA size was determined using the 100bp molecular weight ladder as a marker.

\subsubsection{Phylogenetic Analysis}

Characterization of the phylogenetic groups of the E. coli isolates was determined according to the protocols described by Clermont et al. [8]. Briefly, a single PCR reaction mixture containing 12.5 $\mu \mathrm{L}$ of 2x DreamTaq Master Mix (Promega, USA), $5 \mu \mathrm{L}$ of DNA (approximately $100 \mathrm{ng}$ ), $20 \mu \mathrm{M}$ of each primer in a total volume of $30 \mu \mathrm{L}$. The primer sequences (table 2) were synthesized and 
supplied by Integrated DNA Technologies (Singapore). PCR amplifications were carried out in a Nexus gradient Mastercycler (Eppendorf, USA) using the following conditions: initial denaturation at $94^{\circ} \mathrm{C}$ for $4 \mathrm{~min}$ and 30 cycles for each denaturation at $94^{\circ} \mathrm{C}$ for 5 sec annealing at $57^{\circ} \mathrm{C}$ for 20 sec (group E) or $59^{\circ} \mathrm{C}$ for $20 \mathrm{sec}$ (quadruplex and group C), amplification at $72 \circ \mathrm{C}$ for $1 \mathrm{~min}$, and final extension at $72{ }^{\circ} \mathrm{C}$ for $5 \mathrm{~min}$. The PCR products were analyzed by electrophoresis in $1.5 \%$ agarose gel and image analysis was done using GelDoc ${ }^{\mathrm{TM}}$ EZ Imager (Bio-Rad, USA).

Table 2. Primer sequences used for the quadriplex phylotyping [27]

\begin{tabular}{|c|c|c|c|c|}
\hline PCR reaction & Primer ID & Target & Primer sequence & $\begin{array}{c}\text { Product } \\
\text { (bp) }\end{array}$ \\
\hline \multirow[t]{8}{*}{ Quadriplex } & chuA.1b & chuA & 5'-ATGGTACCGGACGAACCAAC-3' & 288 \\
\hline & chuA.2 & & 5'-TGCCGCCAGTACCAAAGACA-3' & \\
\hline & yjaA.1b & yjaA & 5'-CAAACGTGAAGTGTCAGGAG-3' & 211 \\
\hline & yjaA.2b & & 5'-AATGCGTTCCTCAACCTGTG-3' & \\
\hline & TspE4C2.1b & TspE4.C2 & 5'-CACTATTCGTAAGGTCATCC-3' & 152 \\
\hline & TspE4C2.2b & & 5'-AGTTTATCGCTGCGGGTCGC-3' & \\
\hline & AceK.f & $\operatorname{arp} A$ & 5'-AACGCTATTCGCCAGCTTGC-3' & 400 \\
\hline & ArpA1.r & & 5'-TCTCCCCATACCGTACGCTA-3' & \\
\hline \multirow[t]{2}{*}{ Group E } & ArpAgpE.f & $\operatorname{arp} A$ & 5'-GATTCCATCTTGTCAAAATATGCC-3' & 301 \\
\hline & ArpAgpE.r & & 5'-GAAAAGAAAAAGAATTCCCAAGAG-3' & \\
\hline \multirow[t]{2}{*}{ Group C } & $\operatorname{trpAgpC.1}$ & $\operatorname{trp} A$ & 5'-AGTTTTATGCCCAGTGCGAG-3' & 219 \\
\hline & $\operatorname{trpAgpC.2}$ & & 5'-TCTGCGCCGGTCACGCCC-3' & \\
\hline Internal & $\operatorname{trpBA.f}$ & $\operatorname{trp} A$ & 5'-CGGCGATAAAGACATCTTCAC-3' & 489 \\
\hline control & trpBA.r & & 5'-GCAACGCGGCCTGGCGGAAG-3' & \\
\hline
\end{tabular}

\section{Conclusions}

In conclusion, the detection of carbapenem resistant E.coli in this study shows that these resistant bacteria are not limited to the hospital environment and that CRE is also an emerging problem in farm animals, particularly, in poultry farms. This may raise concern that these carrier food animals may serve as a source of infection and/or colonization for humans. This implies the potential public health risks posed by emerging antimicrobial resistance particularly CRE in food animals and the need for appropriate control and prevention measures to minimize the spread of such resistant bacteria.

Author Contributions: Conceptualization, E. A.; methodology, E.A., A.H., K.K.B.S; investigation, E. A. analysis, resources, E.A., A.H., sample collection, S.I., N.F.K.; writing - original draft preparation, E. A.; writing - review and editing, E.A., A.H., K.K.B.S, N.F.K

Funding: This research received no external funding.

Acknowledgments: We thank Yasmin Khriani, School of Medical Sciences, Universiti Sains Malaysia, Nani Izreen and Salma Zalati, Faculty of Veterinary Medicine, Universiti Malaysia Kelantan for their assistance in conducting this research. 
Conflicts of Interest: The authors declare no conflict of interest.

\section{References}

1. Nordmann, P.; Naas, T.; Poirel, L. Global spread of carbapenemase-producing Enterobacteriaceae. Emerg. Infect. Dis. 2011, 17, 1791-1798.

2. Haque, M.; Sartelli, M.; McKimm, J.; Abu Bakar, M. Health care-associated infections-An overview. Infect. Drug Resist. 2018, 11, 2321-2333.

3. Prestinaci, F.; Pezzotti, P.; Pantosti, A. Antimicrobial resistance: a global multifaceted phenomenon. Path. Glob. Health. 2015, 015109(7), 309-318.

4. WHO (World Health Organization). Factsheet: Antimicrobial Resistance. Updated 13 October 2020, Available from: https://www.who.int/news-room/fact-sheets/detail/antimicrobial-resistance

5. Hsu, L.Y.; Apisarnthanarak, A.; Khan, E.; Suwantarat, N.; Ghafur, A.; Tambyah, P.A. Carbapenem-Resistant Acinetobacter baumannii and Enterobacteriaceae in South and Southeast Asia. Clin. Microbiol. Rev. 2017, 30, 1-22.

6. WHO (World Health Organization). Critically important antimicrobials list. 5th rev. 2017. Available from http://who.int/foodsafety/publications/ antimicrobials-fifth/en/.

7. Zhanel, G.G.; Wiebe, R.; Dilay, L.; Thomson, K.; Rubinstein, E.; Hoban, D.J.; Noreddin, A.M.; Karlowsky, J.A. Comparative review of the carbapenems. Drugs 2007, 67, 1027-1052.

8. Bonardi, S.; Pitino, R. Carbapenemase-producing bacteria in food-producing animals, wildlife and environment: A challenge for human health. Ital. J. Food Saf. 2019, 8, 7956.

9. EFSA Panel on Biological Hazards (BIOHAZ). Scientific opinion on carba-penem resistance in food animal ecosystems. EFSA J. 2013, 11, 3501.

10. Hamza, E.; Dorgham, S.M.; Hamza, D. A. Carbapenemase-producing Klebsiella pneumoniae in broiler poultry farming in Egypt. J. Glob. Antimicrob. Resist. 2016, 7, 8e10.

11. Roschanski, N.; Fischer, J.; Falgenhauer, L.; Pietsch, M.; Guenther, S.; Kreienbrock, L.; Chakraborty, T.; Pfeifer, Y.; Guerra, B.; Roesler, U. H. Retrospective analysis of bacterial cultures sampled in german chicken-fattening farms during the years 2011-2012 revealed additional VIM-1 carbapenemase-producing Escherichia coli and a serologically rough Salmonella enterica serovar infantis. Front. Microbiol. 2018, 9, 538.

12. Tang, B.; Chang, J.; Cao, L.; Luo, Q.; Xu, H.; Lyu,W.; Qian, M.; Ji, X.; Zhang, Q.; Xia, X.; Yang, H. Characterization of an NDM-5 carbapenemase-producing Escherichia coli ST156 isolate from a poultry farm in Zhejiang, China. BMC Microbiol. 2019, 19, 82.

13. Ahmad, K.; Khattak, F.; Ali, A.; Rahat, S.; Noor, S.; Mahsood N.; Somayya, R. Carbapenemases and extended-spectrum $\beta$-lactamase-producing multidrug-resistant Escherichia coli isolated from retail chicken in Peshawar: First report from Pakistan. J. Food Protect. 2018, 81, 1339-45.

14. Poirel, L.; Stephan, R.; Perreten, V.; Nordmann, P. The carbapenemase threat in the animal world: the wrong culprit. J. Antimicrob. Chemother. 2014, 69, 2007-2008.

15. Poirel, L.; Berçot, B.; Millemann, Y.; Bonnin, R. A.; Pannaux, G.; Nordmann, P. Carbapenemase-producing Acinetobacter spp. in cattle, France. Emerg. Infect. Dis. 2012, 18(3), 523-525.

16. Irrgang, A.; Pauly, N.; Tenhagen, B.A.; Grobbel, M.; Kaesbohrer, A.; Hammerl, J.A. Spill-Over from Public Health? First Detection of an OXA-48-Producing Escherichia coli in a German Pig Farm. Microorganisms. 2020, 8(6), 855. 
17. Irrgang, A.; Fischer, J.; Grobbel, M.; Schmoger, S.; Skladnikiewicz-Ziemer, T.; Thomas, K.; Hensel, A.; Tenhagen, B.-A.; Kasbohrer, A.; Käsbohrer, A. Recurrent detection of VIM-1-producing Escherichia coli clone in German pig production. J. Antimicrob. Chemother. 2017, 72, 944-946.

18. K ök, R.; Daniels-Haardt, I.; Becker, K.; Mellmann, A.; Friedrich, A. W.; Mevius, D.; Schwarz, S.; Jurke, A. Carbapenem-resistant Enterobacteriaceaein wildlife, food-producing, and companion animals: A systematic review. Clin. Microbiol. Infect. 2018, 24, 1241-1250.

19. Asadi, A.; ZahraeiSalehi, T.; Jamshidian, M.; Ghanbarpour, R. ECOR phylotyping and determination of virulence genes in Escherichia coli isolates from pathological conditions of broiler chickens in poultry slaughter-houses of southeast of Iran. Vet. Res. Forum Int. Q. J. 2018, 9, 211-216.

20. Coura, F.M.; Diniz, S.A.; Silva, M.X.; Arcebismo, T.L.; Minharro, S.; Feitosa, A.C.; Heinemann,M.B. Phylogenetic group of Escherichia coli isolates from broilers in Brazilian Poultry Slaughterhouse. Sci. World J. 2017, 2017, 2898701.

21. Cordoni, G.; Woodward, M.J.; Wu, H.; Alanazi, M.; Wallis, T.; La Ragione, R.M. Comparative genomics of European avian pathogenic E. coli (APEC). BMC Genom. 2016, 17, 960.

22. Ramadan, H.; Awad, A.; Ateya, A. Detection of phenotypes, virulence genes and phylotypes of avian pathogenic and human diarrheagenic Escherichia coli in Egypt. J. Infect. Dev. Ctries. 2016, 10, 584-591.

23. Walk S.T.; Alm, E.W.; Calhoun, L.M.; Mladonicky, J.M.; Whittam, T. S. Genetic diversity and population structure of Escherichia coli isolated from freshwater beaches. Environ Microbiol. 2007, 9, 2274-88.

24. Carlos, C.; Pires, M.M.; Stoppe, N.C.; Hachich, E.M.; Sato, M.I.; Gomes, T.A.; Amaral, L.A.; Ottoboni, L.M. Escherichia coli phylogenetic group determination and its application in the identification of the major animal source of fecal contamination. BMC Microbiol. 2010, 10, 161.

25. Clinical and Laboratory Standards Institute. Performance standards for antimicrobial susceptibility testing.28thed.CLSI Document M100.Wayne, PA, CLSI, 2018.

26. Kong, R.; So, C.; Law, W.; Wu, R.; Kong, Y.C.R. A sensitive and versatile multiplex PCR system for the rapid detection of enterotoxigenic (ETEC), enterohaemorrhagic (EHEC) and enteropathogenic (EPEC) strains of Escherichia coli. Mar. Pollut. Bull. 1999, 38, 1207-1215.

27. Clermont, O.; Christenson, J.K.; Denamur, E.; Gordon, D.M. The Clermont Escherichia coli phylo-typing method revisited: Improvement of specificity and detection of new phylo-groups. Environ. Microbiol. Rep. 2013, 5, 58-65. 